\title{
Stress and fatigue analyses under wind loading of the dual axis sun tracking system via finite element analysis
}

\author{
Ch. Khelifi" and F. Ferroudji \\ Unité de Recherche en Energie Renouvelables en Milieu Saharien, \\ URERMS, Centre de Développement des Energies Renouvelables, \\ CDER, 01000, Adrar, Algeria \\ *Email: khelifiam@yahoo.fr
}

Phone: +21349362247; Fax: +21349362249

\begin{abstract}
Sun tracking systems (STS) are one of the main components of large-scale photovoltaic (PV)-projects (PV farms) worldwide. PV farms comprise thousands of STS that are subjected to a number of high variable loads, e.g. the loading due to wind. It is also subjected to mechanical and aerodynamic cyclic stresses that can induce fatigue, thus shortening its lifetime. The main objective of this paper is to perform structural stress and fatigue analyses on the dual axis sun tracking system (azimuth-elevation) under selfweight and critical wind loading of $36 \mathrm{~m} / \mathrm{s}(130 \mathrm{~km} / \mathrm{h})$. Plain carbon steel is considered as the material structure. The static stress, damage distributions and fatigue life are obtained by means of Finite Element Analysis (FEA). FEA is carried out using the linear static approach. Fatigue analysis is performed using the Stress-Life method. Simulation results show that the stress resistance of the most fragile material is checked with a safety factor higher than 2 and the structure of the STS can withstand a maximum of 11.905 blocks (repeats) after the specified variable amplitude loading event before fatigue will become an issue. These evaluation results indicate that the sun tracking systems satisfy the design requirements of static strength and are safely within its designed fatigue life.
\end{abstract}

Keywords: Dual Axis Sun Tracking; Fatigue Analysis; FEA; SolidWorks; Stress Analysis.

\section{INTRODUCTION}

Due to increasing environmental pollution caused by carbon dioxide emissions and depleting fossil fuel resources, focus has been set on renewable energy sources such as solar energy, especially solar photovoltaic (PV); renewable energy had recorded an increase in annual growth of $28.7 \%$ [1]. Sun tracking systems (STS) play an important role in the development and application of solar PV to enhance the annual power output [2]. In essence, it is a device that tracks the movement of the sun and used to direct the PV-panels towards the sun all day. STSs are generally classified into two types: one-axis and two-axis tracking devices. A one-axis STS would drive the collector about a one-axis rotation until the sun central ray and the aperture area are coplanar. In contrast, the twoaxis STS, tracks the sun in two axes such that the sun radiation vector is perpendicular to the aperture area as to attain 100\% energy collection efficiency [3]. STS naturally works in outdoor environment, so its structure needs to withstand wind load, snow load, 
temperature and seismic forces. Mechanical fatigue is a subject of great practical importance in the development of statically or dynamically loaded structures [4-7]. To satisfy fatigue requirements of a sun tracking system, generally, the structure is designed either to keep the stress levels below the endurance limit or to ensure the slow crack growth life of their different parts with a safety factor [8]. Fatigue is one of the main forms of deterioration for structures and can be a typical failure mode due to an accumulation of damage [9-12]. During the life cycle of a sun tracker, the variable amplitude of the dynamic wind loading on the deteriorated PV-panel defect can lead to fatigue by damage accumulation in structure details. Such damages might develop into micro cracks and lead to serious fatigue failures for sun tracker components or to the whole structure [13]. For better understanding, predicting, and avoiding fatigue, finite element analysis tool (FEA) has been used. This tool can predict stress concentration areas, and can help design engineers to predict how long their designs are likely to last before experiencing the onset of fatigue.

Present dual axis sun tracking system is detailed in Reference [14]. In the current study, the main objective is to perform stress analysis (von Mises stress) on the STS structure, subjected to its self-weight and a critical wind load of $36 \mathrm{~m} / \mathrm{s}(130 \mathrm{~km} / \mathrm{h})$, in accordance with the EN 1991-1-4 standard [15, 16], and fatigue analysis (variableamplitude fatigue loads) based on its damage distribution and fatigue life of the structure. The static and fatigue analyses for the model is executed using FEA software SolidWorks Simulation $[17,18]$.

\section{MATERIALS AND METHODS}

\section{Stress Analysis on the STS}

In order to evaluate the fatigue life of a structure, it is necessary to calculate an accurate stress or strain state. Usually, stress analysis can be categorized into static and dynamic analysis according to types of loads. The purpose of a static analysis is to guarantee the strength, stiffness and stability of a structure subjected to external static loading; and structural response is computed by solving equilibrium static equation written as follows $[19,20]$ :

$$
[K]\{u(t)\}=\{f(t)\}
$$

where, $[\mathrm{K}]$ is the stiffness matrix, $\{\mathrm{u}(\mathrm{t})\}$ is the displacement vector and $\{\mathrm{f}(\mathrm{t})\}$ is the load vector

The structure of the tracker is analysed using FEA static method from SolidWorks Simulation software to check the stresses on the sun tracking system under maximum wind pressure of $800 \mathrm{~N} / \mathrm{m}^{2}$ at $36 \mathrm{~m} / \mathrm{s}$. The first step in FEA analysis is to assign a material to the tracker model, whereby plain carbon steel is chosen according to availability, hardness and machinability [21]; with elastic modulus, E of $220 \mathrm{GPa}$; Poisson's ratio of 0.28 ; and density of $7800 \mathrm{~kg} . \mathrm{m}^{-3}$ [22]. Then the definition of boundary conditions at the base of the assembly is fixed (constraints/fixtures), while hinges restraints are defined at cylindrical face (principal axis, hydraulic actuator axis and etc.). These fixtures constrain all translational and all rotational degrees of freedom. Therefore, the sun tracker would remain in a static and fixed position. The weight of the PV-panel considered is such that all the parts (frame) are directly attached to the PV-panel (G). A total of $36 \mathrm{PV}$-panels are mounted onto a $12 \times 3$ matrix. The tracker design features PV-panels, each weighing $8 \mathrm{~kg}$, 
with respect to the following load conditions: (i) the tracker structure weight is around $1,789 \mathrm{~kg}$. Therefore, the constant total dead load of PV-panels on the structure is 2,077 $\mathrm{kg}$; (ii) wind loads create random time-varying loading on the structure. The amount of load subjected on the structure depends on the maximum wind speed $\left(\mathrm{V}_{\max }\right)$ and the angle of attack of the wind, inclination of the solar panels, structural design, geographical factor and proximity with neighbourhood structures. It also depends on the density of the air, but the variations due to these factors are assumed to be negligible specifics of each geographical region. Based on this, a maximum wind pressure $\left(\mathrm{P}_{\max }\right)$ [23]:

$$
P=0.5 \cdot C_{d} \cdot \rho_{\text {air }} \cdot v_{\text {Wind }}^{2}
$$

where, $C_{d}$ is the drag factor, $\rho_{\text {air }}$ is the density of the air, and $v_{\text {wind }}$ is the wind speed The sun tracking structure analysis is designed to operate under extreme climatic loading with maximum wind pressure of $800 \mathrm{~N} / \mathrm{m}^{2}$ at $36 \mathrm{~m} / \mathrm{s}$ and elevation rotation angle about $50^{\circ}$ because this angle represents the critical orientation of the swept area facing the wind. The model of the STS, loadings and boundary condition are shown in Figure 1. A finite element mesh created for the system is shown in Figure 2. The mesh consisted of 217451 nodes and 116520 units for a total of 736837 degree of freedom (DOF). The global size of the element $(77,719$ to $388,596 \mathrm{~mm})$ is chosen based on the geometrical size of smallest part of structure. The mesh consists of solid 3D tetrahedral elements with ten DOF at each node.

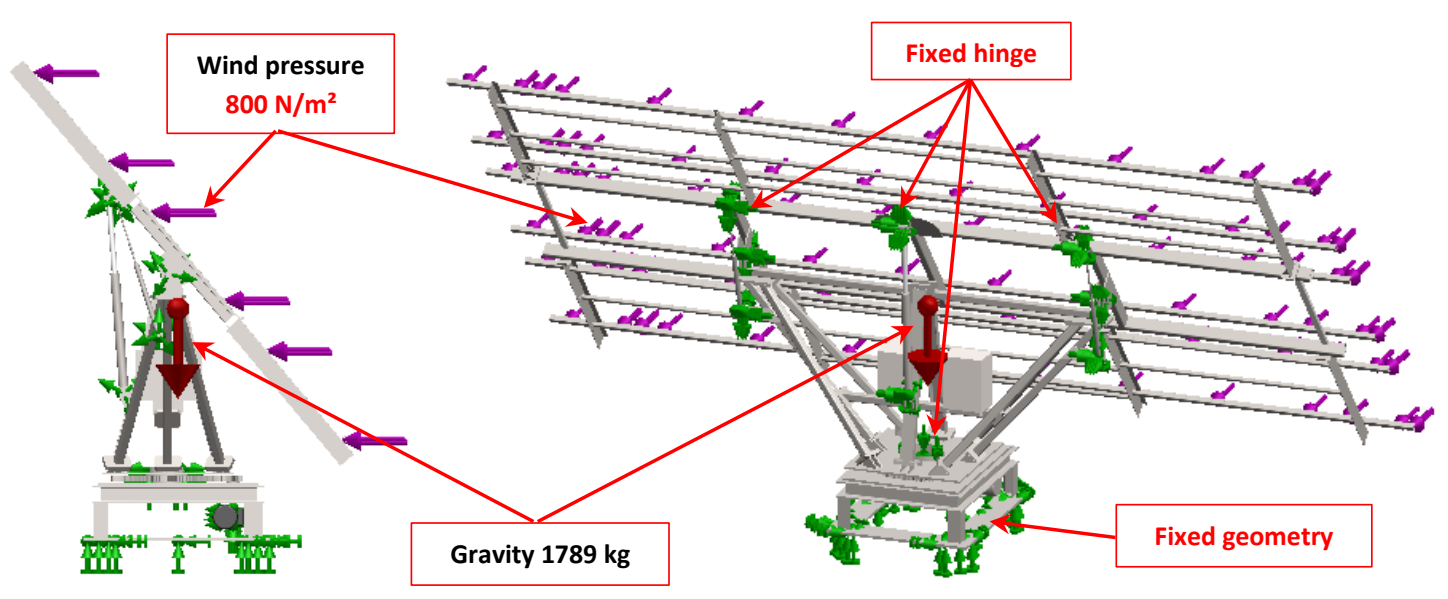

Figure 1. Applied loads and constraints on sun tracking system.

\section{Fatigue Analysis on the STS}

Structures of the STSs are subjected to time-varying wind pressures that result in stress cycles at critical structural details. Hence, pertaining to wind load time history, dynamic finite element analysis needs to be performed to obtain stress time histories for fatigue evaluation. The finite element code of SolidWorks Simulation is used to obtain the damage distribution and fatigue life on the sun tracking system. Constant amplitude fatigue loading is defined as fatigue under cyclic loading with constant amplitude and a constant mean load. However, engineering components are usually subjected to variable amplitude loading, which can be defined by complex loading histories of varying cyclic stress amplitudes, mean stresses and loading frequencies [23, 24]. There are two main approaches to fatigue life determination, i.e., the first is based on stress, the so-called 
Stress-Life method (S-N curve, nominal stress), also known as a Wöhler curve while the second is based on strain, the so-called Strain-Life method (Local-Stress-Strain) [25, 26].

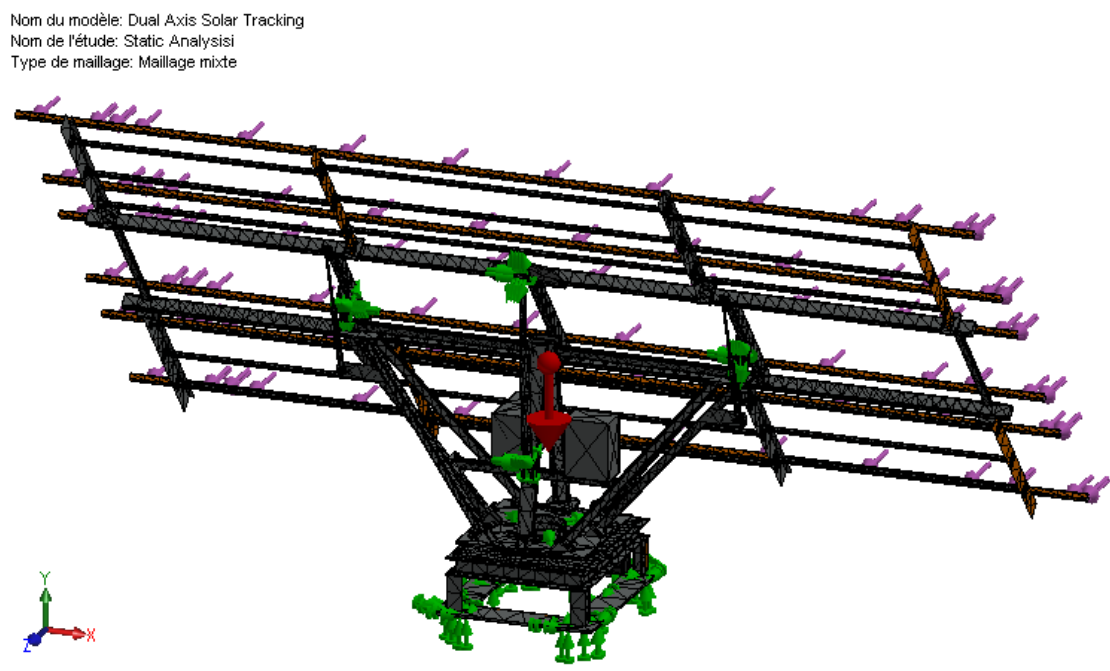

Figure 2. The finite element mesh model of the sun tracking system.

SolidWorks/Simulation uses S-N curve method. In the case of S-N curves of materials and parts, a few materials in the SolidWorks material library already have predefined fatigue $\mathrm{S}-\mathrm{N}$ curves. These materials are identified by a suffix $(\mathrm{SN})$ attached at the end of their names in the material list of the material library. The reference for $\mathrm{S}-\mathrm{N}$ curves is the Atlas of Fatigue Curves, ASM International [26, 27]. The basic material for $\mathrm{S}-\mathrm{N}$ curve established in our current simulation is Plain Carbon Steel as depicted in Figure 3.

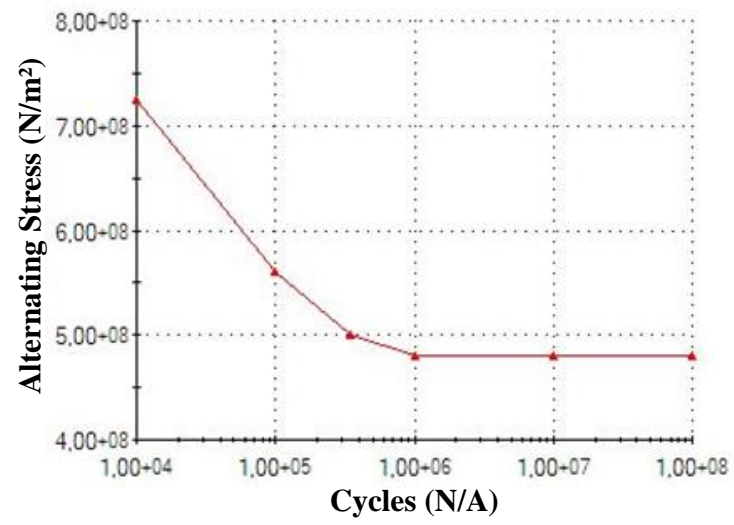

(a)

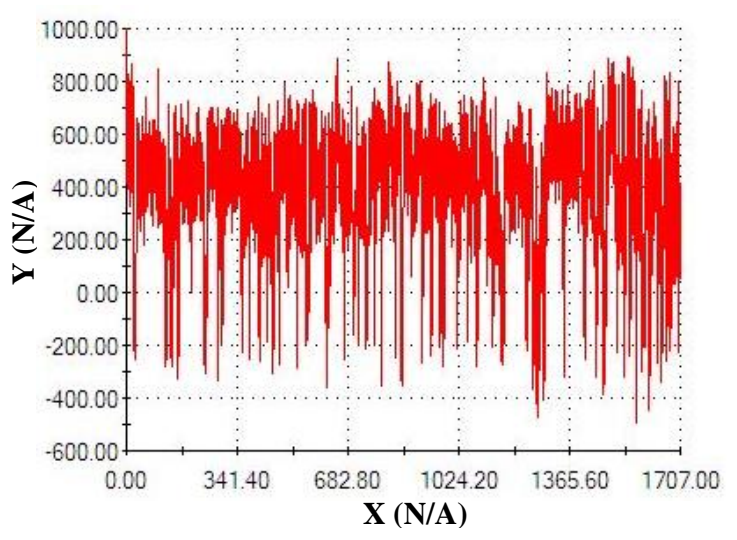

(b)

Figure 3. Damage factor contours of the sun tracking system: (a) S-N curve; (b) Load history curve.

The fatigue damage is assessed using the Rain-flow, the most popular and probably the best method of cycle counting procedure and the Palmgren-Miner linear damage cumulating theory [28]. The material of sun tracking system is Plain Carbon Steel, and the Gerber (generally suitable for ductile materials) mean stress correction method is applied in this analysis, thus the formula becomes [29]: 


$$
S_{c a}=\frac{S_{a}}{1-\left(\frac{S_{\text {mean }}}{S_{u}}\right)^{2}}
$$

where, $\mathrm{S}_{\mathrm{ca}}$ is the corrected alternating stress (based on zero mean)

$\mathrm{S}_{\mathrm{a}}=\left(\mathrm{S}_{\max }-\mathrm{S}_{\min }\right) / 2$ is the alternating stress

$\mathrm{S}_{\text {mean }}=\left(\mathrm{S}_{\text {max }}+\mathrm{S}_{\text {min }}\right) / 2$ is the mean stress

$\mathrm{S}_{\mathrm{u}}$ is the ultimate strength

\section{RESULTS AND DISCUSSION}

The stress state of the structure of the STS was attained as a result of the static analysis and. The von Mises equivalent stress distribution is shown in Figure 4. The stress values are determined according to von Mises criterion expressed by Eq. (3):

$$
\sigma_{e}=\left\{\left[\left(\sigma_{x}-\sigma_{y}\right)^{2}+\left(\sigma_{y}-\sigma_{z}\right)^{2}+\left(\sigma_{z}-\sigma_{x}\right)^{2}+6\left(\tau_{x y}^{2}+\tau_{y z}^{2}+\tau_{z x}^{2}\right)\right] / 2\right\}^{\frac{1}{2}}
$$

Where:

$$
\{\sigma\}=\text { stress vector }=\left[\begin{array}{llllll}
\sigma_{x} & \sigma_{y} & \sigma_{z} & \sigma_{x y} & \sigma_{y z} & \sigma_{z x}
\end{array}\right]^{T}
$$

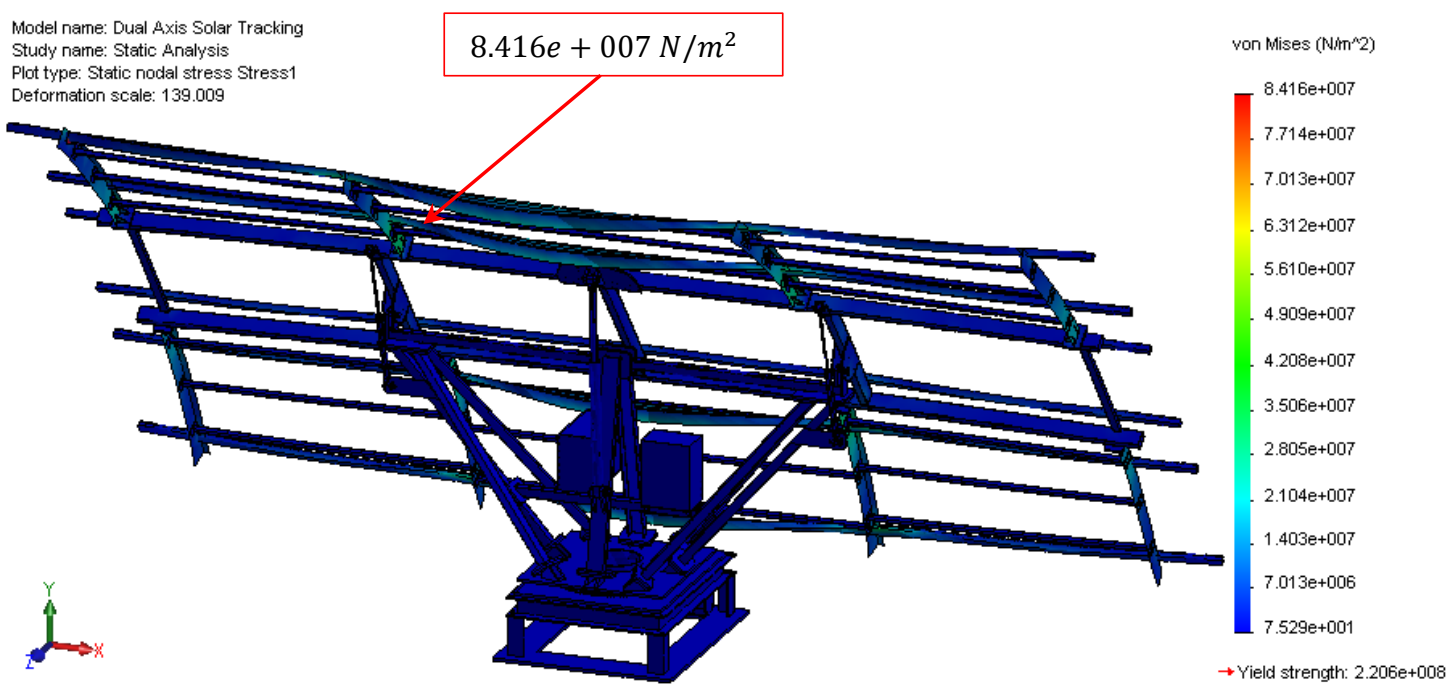

Figure 4. von Mises equivalent stress distribution on the sun tracking system.

As shown in the figure, the maximum von Mises stress for the tracker is 84.16 MPa. This value is distributed in the embedment of the beam that carries the PV-panel. This is in good agreement with the theory of bending beams (a beam that is fixed at one end and under uniform load). The structure does not undergo structural failure as these stress values are far below the yield strength of Plain Carbon Steel (220.6 MPa). The safety factor is defined as 2.51 (minimum value), to ensure that the material is always above yield value. Therefore, the design of sun tracking system satisfies the strength requirement. After the structure of the STS passes the strength test, the fatigue simulation will indicate the regions of the material in danger of fatigue failure. In the event of variable amplitude (and not constant amplitude), the life results given by the fatigue analysis is in terms of blocks instead of cycles, where blocks are defined as the total load history (including the number of repeats of the event in the curve). 
Figure 5 presents the measured fatigue damage of the sun tracking system, which is defined as the design life divided by the available life. A value of 1 indicates that the defined fatigue events consume $100 \%$ of the life of the sun tracker. It can be seen in this figure that the minimum damage of $0.0009 \%$ and the maximum damage occurred about $8.4 \%$ in the contact area (principal axis) between the support of the grid (upper frame) and the support in V; this contact area is a hinge (pivot) connection. The Total Life simulation shows how many load cycles have to be applied till fatigue. Figure 6 shows the available life for the given fatigue analysis. As can be seen from the figure, the sun tracking system can withstand a maximum of $1 /$ ( $\max$ damage $)=0.084=11.905$ blocks (repeats) of the specified variable-amplitude loading event before fatigue becomes an issue [30]. This value must be seen as an upper bound. Hence the sun tracking system design is safely within its designed fatigue life.

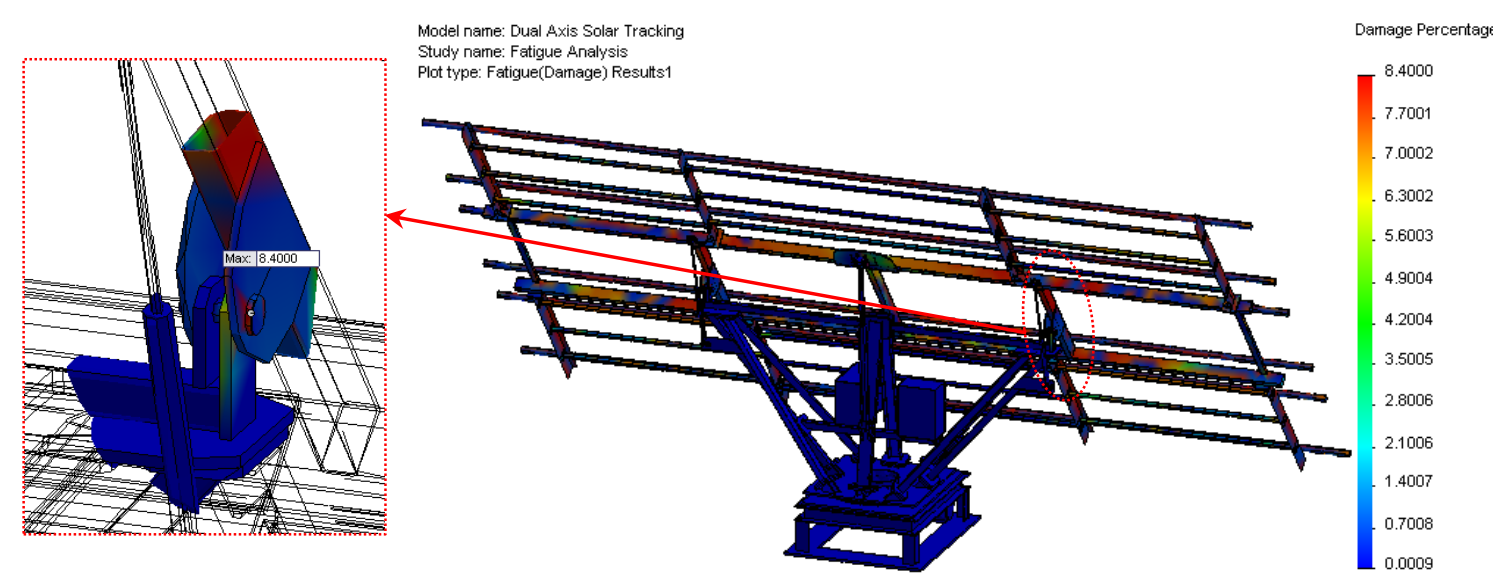

Figure 5. Damage factor contours of the sun tracking system.

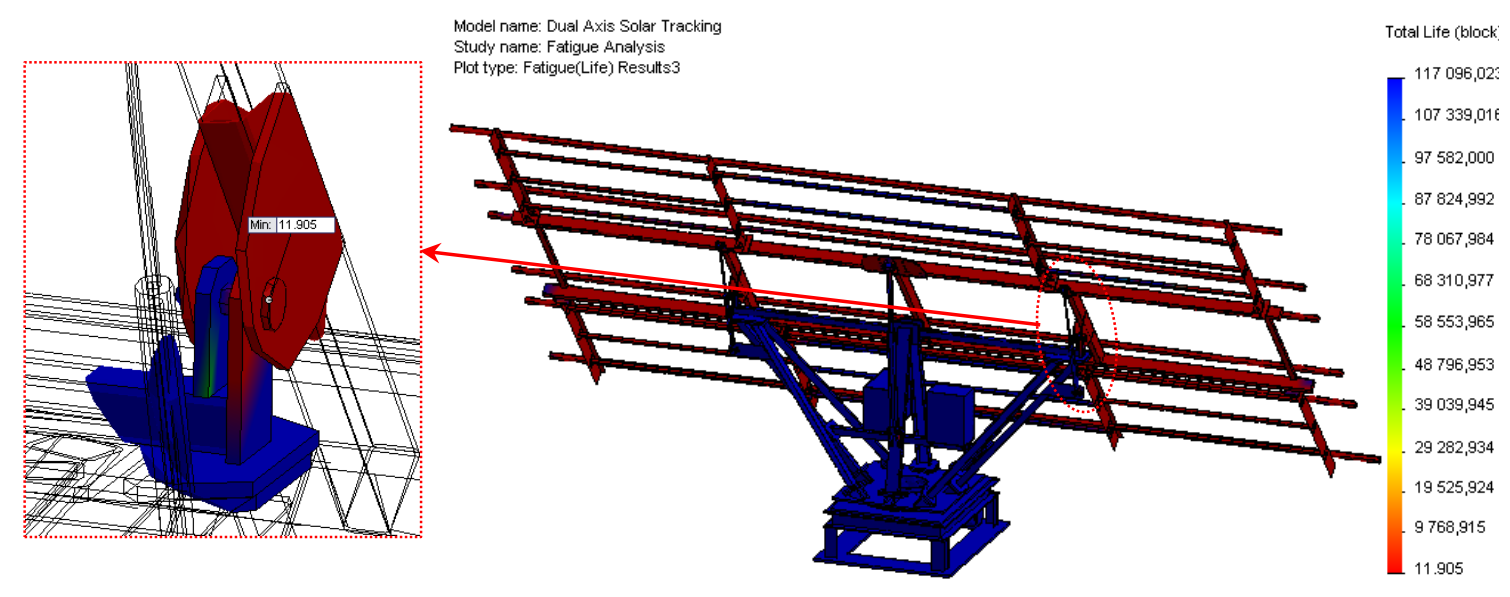

Figure 6. The fatigue life of the sun tracking system.

\section{CONCLUSIONS}

This work has focused on stress and fatigue behaviours of dual-axis a sun tracking system under variable amplitude loading based on finite element analysis. The FEA of this sun tracking had been carried out via SolidWorks Simulation software. The stress analysis 
results show that the criterion of von Mises resistance of the most fragile material of the sun tracker is checked with a safety factor higher than 2 . The fatigue analysis results also show that the sequence of fatigue events is expected to consume $8.4 \%$ of the life of the sun tracking system, whereby it is likely to fail due to fatigue after 11.905 blocks (repeats). These evaluation results indicate that the sun tracking system satisfies the design requirements of static strength and is safely within its designed fatigue life. This has essentially laid the foundation for future work in terms of structural optimization, structural dynamic analysis and dynamic fatigue analysis.

\section{ACKNOWLEDGEMENTS}

The present work has been funded by the Renewable Energy Research Unity in Sahara Medium (URERMS) linked to the CDER (Renewable Energy Development Center, http://portail.cder.dz), governmental research center of Algeria. The authors are scientific researchers in renewable energy and sustainable development, working in URERMS. The authors thank the reviewers for their helpful suggestions for improvement of this paper.

\section{REFERENCES}

[1] Martinot E. Renewables 2005: Global status report. REN21 Renewable Energy Policy Network/Worldwatch Institute2015. p. 14.

[2] Lin C-K, Dai C-Y, Wu J-C. Analysis of structural deformation and deformationinduced solar radiation misalignment in a tracking photovoltaic system. Renewable Energy. 2013;59:65-74.

[3] Barsoum N. Fabrication of dual-axis solar tracking controller project. Intelligent Control and Automation. 2011;2:57-68.

[4] Mohamed SAN, Abdullah S, Arifin A, Ariffin AK, Padzi MM. Characterization of the biaxial fatigue behaviour on medium carbon steel using the strain-life approach. International Journal of Automotive and Mechanical Engineering. 2016;13:3262-77.

[5] Wor LC, Rahman MM. Stress behavior of tailor-welded blanks for dissimilar metals using finite element method. International Journal of Automotive and Mechanical Engineering. 2015;11:2541-54.

[6] Ahmad MIM, Arifin A, Abdullah S. Evaluating effect of magnetic flux leakage signals on fatigue crack growth of mild steel. Journal of Mechanical Engineering and Sciences. 2016; 10(1):1827-34..

[7] Yusof MFM, Jamaludin N, Abdullah S, Hanafi ZH, Zain MSM. Monitoring and Assessment of Acoustic Emission Signatures during Fatigue Mechanism of API5LX70 Gas Pipeline Steel. Journal of Mechanical Engineering and Sciences. 2012;2:237-50.

[8] Bonte M, De Boer A, Liebregts R. Determining the von Mises stress power spectral density for frequency domain fatigue analysis including out-of-phase stress components. J Sound Vib. 2007;30:379-86.

[9] Kamal M, Rahman MM. Multiaxial fatigue life modelling using hybrid approach of critical plane and genetic algorithm. Fatigue and Fracture of Engineering Materials and Structures. 2016;39:479-90.

[10] Sivananth V, Vijayarangan S. Fatigue Life Analysis and Optimization of a Passenger Car Steering Knuckle under Operating Conditions. International Journal of Automotive and Mechanical Engineering. 2015;11:2417-29. 
[11] Mohamed MA, Manurung YHP, Ghazali FA, Karim AA. Finite Element-Based Fatigue Life Prediction of a Load-Carrying Cruciform Joint. Journal of Mechanical Engineering and Sciences. 2015;8:1414-25.

[12] Kamal M, Rahman MM. Fatigue life estimation based on continuum mechanics theory with application of genetic algorithm. International Journal of Automotive and Mechanical Engineering. 2015;11:2686-98.

[13] Xiong JJ, Shenoi R. Fatigue and fracture reliability engineering. London: Springer Science \& Business Media; 2011.

[14] Ferroudji F, Ouattas T, Khelifi C. Design, Modeling and Finite Element Static Analysis of a New Two Axis Solar Tracker Using SolidWorks/COSMOSWorks. Applied Mechanics and Materials. 2014;446-447:738-43.

[15] mecasolar. Solar Tracker MS-2 Tracker 10 and 10+. 2009.

[16] EUROCODES. Eurocode 1: Actions on Structures, General Actions - Part 1-4: Wind Actions. Brussels COMITE EUROPEEN DE NORMALISATION; 2005. p. 1 - 146.

[17] SolidWorks. Baker Avenue, Concord: SolidWorks Corporation. http://www.solidworks.com/.

[18] Petrova RV. Introduction to Static Analysis Using SolidWorks Simulation. Boca Raton: CRC Press; 2014.

[19] Wilson EL. Three-dimensional static and dynamic analysis of structures. 3rd ed. Berkeley: Computers and Structures, Inc.; 2002.

[20] Biagini P, Borri C, Facchini L. Wind response of large roofs of stadions and arena. Journal of Wind Engineering and Industrial Aerodynamics. 2007;95:871-87.

[21] Khelifi C, Ouali M, Ferroudji F, Adjlout L. Modal Analysis of a Small Savonius Aerogenerator by Using SolidWorks Simulation. Applied Mechanics and Materials. 2015;806:214-21.

[22] Lee H-H. Mechanics of Materials Labs with SOLIDWORKS Simulation 2015. New York: SDC Publications; 2015.

[23] Kamal M, Rahman M, Rahman A. Fatigue life evaluation of suspension knuckle using multi body simulation technique. Journal of Mechanical Engineering and Sciences. 2012;3:291-300.

[24] Gong B, Li Z, Wang Z, Wang Y. Wind-induced dynamic response of Heliostat. Renewable Energy. 2012;38:206-13.

[25] Lalanne C. Mechanical vibration and shock analysis, fatigue damage: John Wiley \& Sons; 2010.

[26] Stephens RI, Fatemi A, Stephens RR, Fuchs HO. Metal fatigue in engineering. London: John Wiley \& Sons; 2000.

[27] Boyer HE. Atlas of Fatigue Curves. New York: ASM International; 1985.

[28] Wang H, Xue C, Jiang W. Fuzzy Fatigue Reliability Analysis for a Landing Gear Structure. 3rd International Joint Conference on Computational Science and Optimization IEEE; 2010. p. 112-5.

[29] Gerber W. Investigation of the Allowable Stresses in Iron Construction, . Germany: Bayer. Arch. Ing. Ver. (Bavarian Archives of Engineering Associates); 1874.

[30] Handbook A. Properties and selection: irons, steels, and high performance alloys 1990. 